\title{
IN VITRO EVIDENCES FOR SIMVASTATIN AND LOSARTAN POTASSIUM INTERACTION AND ITS IN VIVO IMPLICATIONS
}

\author{
M. SAEED ARAYNE*1, NAJMA SULTANA² UROOJ HAROON ${ }^{3}$ AND BATOOL ZAIDI ${ }^{1}$ \\ 'Department of Chemistry, University of Karachi, Karachi-75270, Pakistan \\ ${ }^{2}$ Department of Pharmaceutical Chemistry, Research Institute of Pharmaceutical Sciences, Faculty of Pharmacy, University of Karachi \\ ${ }^{3}$ Departament of Chemistry, Federal Urdu University for Arts, Science of technology, Karachi-75300, Pakistan \\ (Received: April 1, 2009 - Accepted: October 8, 2009)
}

\begin{abstract}
In the present paper, we describe the in vitro availability of simvastatin, a potent HMG-CoA reductase inhibitor, in presence of losartan potassium, which is a non-peptide angiotensin II receptor antagonist. These studies were carried out at 37,48 and $60^{\circ} \mathrm{C}$ in different $\mathrm{pH}$ environments simulating human body compartments. The reactions were studied by UV spectroscopy and the availability of both drugs in presence of each other was determined by deriving a simultaneous equation for two component system through modification of Beer's law. The interactions were further characterized by IR and $\mathrm{H}^{1} \mathrm{NMR}$ spectroscopic techniques. It was observed that availability of simvastatin in presence of losartan at $37^{\circ} \mathrm{C}$ in simulated gastric juice, at pH 7.4 and $\mathrm{pH} 9.0$ was blocked by losartan through the formation of a charge-transfer complex while the availability of losartan in turn was immensely increased. In $\mathrm{pH} 4.0$ these effects were reversed, availability of simvastatin increased and the availability of losartan was depressed. Similar results were observed at higher temperatures.
\end{abstract}<smiles>CCC(C)(C)C(=O)OC1CC(C)C=C2C=CC(C)C(CCC(O)CC(O)CC(O)O)C21</smiles>

a<smiles>CCCCC1NC(Cl)C(C(=O)O)N1C</smiles><smiles>CN(C)CC1CCC(c2ccccc2-c2nn[nH]n2)CC1</smiles>

b buffers ( $\mathrm{pH} 1.0,4.0,7.4$ and 9.0$)$

temp $\left(37,48\right.$ and $\left.60{ }^{\circ} \mathrm{C}\right)$

$\mathrm{a}=$ active metabolite of simvastatin

$\mathrm{b}=$ active metabolite of losartan

$c=$ Hydrogen bonded charge transfer complex

Keywords: simvastatin, losartan, drug interactions, charge-transfer complex

\section{INTRODUCTION}

Simvastatin, $\quad\left[1 \mathrm{~S}-\left\{1 \alpha, \quad 3 \alpha, \quad 7 \beta, \quad 8 \beta \quad\left(2 \mathrm{~S}^{*}, \quad 4 \mathrm{~S}^{*}\right), \quad 8 \alpha\right\}\right]-1,2,3,7,8,8 \mathrm{a}$ Hexahydro-3, 7-dimethyl-8- [2-(tetrahydro-4-hydroxty-6-oxo-2H-pyran-2-yl) ethyl]-1-naphthalenyl2,2 dimethylbutanoate, is an inactive lactone prodrug, metabolized after oral ingestion to the dihydroxy open acid form which inhibits 3-hydroxy-3-methylglutaryl coenzyme A (HMG-CoA) reductase, an enzyme which catalyses the rate-limiting step in the biosynthesis of cholesterol ${ }^{1}$ (fig 1). Simvastatin is highly effective in reducing total plasma cholesterol (total-C), low-density lipoprotein cholesterol (LDL-C), triglycerides (TG), very-low-density lipoprotein cholesterol (VLDL-C) and increasing highdensity lipoprotein cholesterol (HDL-C) in heterozygous familial forms of hypercholesterolemia, and in mixed hyperlipidemia ${ }^{2,3}$.

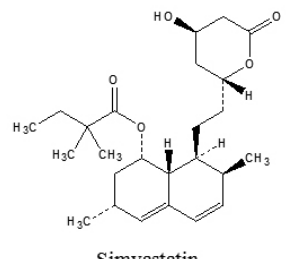

Simvastatin

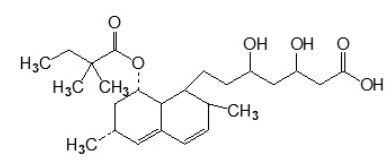

its active metabolite
Figure 1
Losartan, 2-butyl-4-chloro-1-((2'-(1H-tetrazol-5-yl)(1,1'-bi-phenyl)-4-yl) methyl)-1H-imidazole-5-methanol monopotassium salt is an orally active antagonist that binds selectively and specifically to the $\mathrm{AT}_{1}$ subtype of angiotensin II receptor antagonis ${ }^{4,5}$ (fig 2). Oxidation of the 5-hydroxymethyl groups on the imidazole ring results in the active metabolite of losartan.
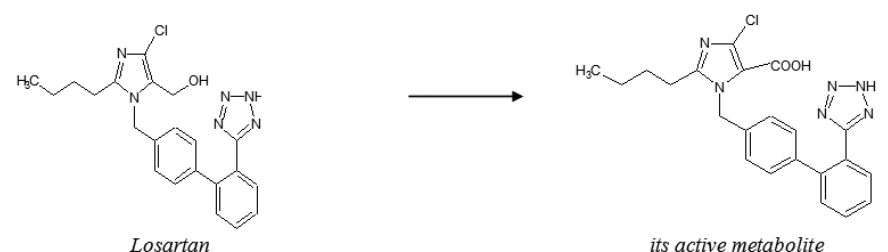

Figure 2

Simvastatin is metabolized by the cytochrome P450 isoenzyme CYP3A4, interactions may occur with drugs that inhibit this enzyme including ketoconazole, an anti-fungal sterol, synthetic inhibitor of the azol group ${ }^{6}$, mibefradil $^{7}$, cyclosporine ${ }^{8}$, coumarin anticoagulants ${ }^{9}$, erythromycin and other macrolides ${ }^{10}$ and aspirin ${ }^{11}$. HIV-protease inhibitors are CYP3A4 inhibitors and may affect the metabolism of simvastatin like nelfinavir ${ }^{12}$.

There are many evidences that points to interplay between hypercholesterolemia and hypertension, acting through the renin-angiotensin system (RAS), to increase cardiovascular risk ${ }^{13,14}$. It is envisaged that a combination therapy of an ARB and a statin would find utilization in people with cardiovascular risk factors ${ }^{15}$.

In present paper, we describe the in vitro availability of simvastatin and losartan potassium in presence of each other. The later drug is most commonly 
co-administered with statin drugs and simvastatin is the common drug of choice. These interactions were carried out in different $\mathrm{pH}$ environments simulating empty and full stomach juice $(\mathrm{pH} 1.0$ and 4.0) intestinal juice $(\mathrm{pH}$ $9.0)$ and blood $\mathrm{pH}$ (7.4) at physiological and elevated temperatures. The results show formation of a charge-transfer complex as the availability of simvastatin was depressed, while availability of losartan was significantly increased.

\section{EXPERIMENTAL}

\section{Materials and equipment}

Simvastatin reference standard was provided by our supervisor Prof Dr. Saeed Arayne. Losartan potassium reference standard was a kind gift from Pharmevo Karachi. Simvastatin and Losatan potassium $\left(\right.$ zocor $^{\circledR} 10 \mathrm{mg}$ and Tancin $^{\circledR} 50 \mathrm{mg}$ ) tablets were purchased from the market. All the reagents used were of analytical grade. All the glassware was washed with chromic acid followed by a thorough washing with de-ionized water which was freshly prepared in the laboratory.

Melting point was recorded on a Gallenkamp apparatus. Dissolution test apparatus manufactured according to B.P 2006 standards $^{16}$, with little modification ${ }^{17}$ was used for interaction studies. UV/Visible spectrophotometer (Shimadzu 1601 coupled with a P IV - PC and loaded with UVPC version 3.9 software) was used to quantitate drug contents.

Infrared spectra of simvastatin, losartan and their derivative were measured using an FT-IR spectrophotometer (shimadzu prestige-21 200 VCE coupled to a P IV- PC and loaded with IR solution version 1.2 software). The disks were placed in holder directly in the IR laser beam. Spectra were recorded at a resolution of $2 \mathrm{~cm}^{-1}$ and 50 scans were accumulated.

${ }^{1} \mathrm{H}$ nuclear magnetic resonance (NMR) spectroscopy was performed at $500 \mathrm{MHz}$ on a Bruker AMX $500 \mathrm{MHz}$ spectrometer using TMS as an internal standard and the compounds dissolved in deuterated methanol.

Thin layer chromatography (TLC) was performed on HSF-254 TLC plate and compounds visualized under UV lamp.

Synthesis

Simvastatin (1mmole) and losartan (1 mmole) were separately dissolved in $40 \mathrm{ml}$ methanol. The solutions were mixed with constant stirring in a round bottomed flask and refluxed. The progress of the reaction was monitored by TLC. After the completion of the reaction, solvent was evaporated and the product was purified by re-crystallization in methanol: chloroform $(8: 2)$.

\section{Quantitation of interacting drugs}

\section{Reference standards}

Simvastatin and losartan potassium both obeyed Beer's law at their respective $\lambda \max (232,239,247 \mathrm{~nm})$ and $205-206 \mathrm{~nm}$ respectively in the concentration range of $10^{-4}-10^{-5}$ moles in all buffer systems under study. For quantitation, molar absorptivity of simvastatin was calculated using its reference standard at its respective $\lambda_{\max }$ and also at the wavelength in which losartan gives maximum absorption. In similar way, molar absorptivity of losartan was calculated using its reference standard at its characteristic $\lambda_{\max }$ and also at the absorption maxima of simvastatin (table1).

Table 1. Molar absorptivities of Simvastatin and Losartan.

\begin{tabular}{|c|c|c|c|c|c|}
\hline \multirow{2}{*}{ S. No } & \multirow{2}{*}{$\begin{array}{l}\text { Dissolution } \\
\text { mediums }\end{array}$} & \multicolumn{2}{|c|}{$<\longrightarrow$ Simvastatin $\longrightarrow>$} & \multicolumn{2}{|c|}{$<\longmapsto$ Losartan $\longrightarrow$} \\
\hline & & $\lambda$ & $\varepsilon$ moles $^{-1} \mathrm{Lcm}^{-1}$ & $\lambda$ & $\varepsilon$ moles $^{-1} \mathrm{Lcm}^{-1}$ \\
\hline \multirow{4}{*}{1} & \multirow{4}{*}{$\begin{array}{l}\text { Simulated gastric } \\
\text { juice }\end{array}$} & $232 \mathrm{~nm} *$ & 17100 & $206 \mathrm{~nm} *$ & 19840 \\
\hline & & $239 \mathrm{~nm} *$ & 19000 & $232 \mathrm{~nm}$ & 24245 \\
\hline & & $247 \mathrm{~nm} *$ & 12800 & $239 \mathrm{~nm}$ & 16579 \\
\hline & & $206 \mathrm{~nm}$ & 5017 & $247 \mathrm{~nm}$ & 13305 \\
\hline \multirow{4}{*}{2} & \multirow{4}{*}{$\mathrm{pH} 4.0$} & $232 \mathrm{~nm} *$ & 16500 & $206 \mathrm{~nm} *$ & 22303 \\
\hline & & $239 \mathrm{~nm} *$ & 18400 & $232 \mathrm{~nm}$ & 24047 \\
\hline & & $247 \mathrm{~nm} *$ & 12700 & $239 \mathrm{~nm}$ & 16857 \\
\hline & & $206 \mathrm{~nm}$ & 3266 & $247 \mathrm{~nm}$ & 13677 \\
\hline \multirow{4}{*}{3} & \multirow{4}{*}{ pH 7.4} & $232 \mathrm{~nm} *$ & 16250 & $206 \mathrm{~nm} *$ & 21218 \\
\hline & & $239 \mathrm{~nm} *$ & 18200 & $232 \mathrm{~nm}$ & 21245 \\
\hline & & $247 \mathrm{~nm} *$ & 12000 & $239 \mathrm{~nm}$ & 15541 \\
\hline & & $206 \mathrm{~nm}$ & 5334 & $247 \mathrm{~nm}$ & 13037 \\
\hline \multirow{4}{*}{4} & \multirow{4}{*}{ pH 9.0} & $232 \mathrm{~nm} *$ & 17800 & $206 \mathrm{~nm} *$ & 21218 \\
\hline & & $239 \mathrm{~nm} *$ & 19950 & $232 \mathrm{~nm}$ & 22888 \\
\hline & & $247 \mathrm{~nm} *$ & 13400 & $239 \mathrm{~nm}$ & 16700 \\
\hline & & $206 \mathrm{~nm}$ & 5334 & $247 \mathrm{~nm}$ & 13985 \\
\hline
\end{tabular}

$*=\lambda_{\text {max }}$ of drug

\section{Availability studies}

In the first set of experiments, in vitro availability of simvastatin and losartan potassium were studied individually in different dissolution mediums, each being $1000 \mathrm{ml}$ of simulated gastric juice, buffers of $\mathrm{pH} \mathrm{4.0,7.4} \mathrm{and}$ simulated intestinal juice. Samples were withdrawn periodically at an interval of 15 minutes for 180 minutes. The volume of dissolution fluid was maintained by adding an equal amount of dissolution fluid withdrawn, which had previously been maintained at the same temperature in the same bath. The absorbance of the sample withdrawn was measured at their $\lambda_{\max }$ and analyzed for its contents on a UV/visible spectrophotometer.

\section{Interaction studies}

The in vitro interaction of simvastatin with losartan potassium was carried out in the same set of dissolution mediums. In each set of experiment simvastatin tablet was added at zero time to the dissolution medium already maintained at $37^{\circ} \mathrm{C}$ while losartan potassium was added after 15 minutes time interval. Aliquots were withdrawn and assayed for both the drugs. The above procedure was repeated at 48 and $60^{\circ} \mathrm{C}$ keeping the other experimental conditions constant. $\%$ availability of each drug versus time was calculated in each set of experiment. 


\section{RESULTS AND DISCUSSION}

There are number of assay methods reported in the literature for $\operatorname{simvastatin}^{18-23}$ and losartan ${ }^{24-27}$. Spectrophotometric techniques provide practical and significant economic advantages over other methods; therefore, they are a frequent choice for analyses. Accordingly, in present studies we employed UV spectroscopic methods for quantitation of both drugs.

The absorption maxima of simvastatin are reported to be at 231,238 and $247 \mathrm{~nm}$. The $\lambda_{\max }$ at $238 \mathrm{~nm}$ is typical for substituted diene chromophore, owing to a $\pi-\pi^{*}$ transition. The $\lambda$ at 231 and $247 \mathrm{~nm}$ are observed due to the presence of lactone and ester group respectively due to $\mathrm{n}-\pi^{*}$ transition; oxygen acts as an auxochrome which go in conjugation with $\mathrm{C}=\mathrm{O}$ group. In our studies these maxima were observed at 232, 239 and $247 \mathrm{~nm}$, which may arise due to solvent or instrument variation; $\mathrm{pH}$ also plays a significant role in deviation of absorption values. On the other hand, the reported maximum absorption for losartan at $206 \mathrm{~nm}$ is due to the presence of tetrazole ring.

During the analysis, it was observed that the $\lambda$ of simvastatin and losartan was quite far apart. Accordingly to quantify both drugs at the same time, following simultaneous equations for two component system was developed by modifying Beers equation:

$$
\text { and } \mathrm{C}_{\mathrm{a}}=\frac{\mathrm{A}_{239} \mathrm{~b}_{2}-\mathrm{A}_{206} \cdot \mathrm{b}_{1}}{\mathrm{C}_{\mathrm{b}}=\frac{\mathrm{A}_{239} \mathrm{a}_{2}-\mathrm{A}_{206} \cdot \mathrm{a}_{1}}{\mathrm{a}_{2} \mathrm{~b}_{1}-\mathrm{a}_{1} \mathrm{~b}_{2}}}
$$

Where $\mathrm{Ca}$ and $\mathrm{Cb}$ were the concentrations of simvastatin and losartan, a and $\mathrm{a}_{2}$ were the molar absorptivites of simvastatin at 239 and $206 \mathrm{~nm}$, while $b_{1}$ and $b_{2}$ were that of losartan potassium at 239 and $206 \mathrm{~nm}$. These equations were used to measure the quantities of simvastatin (at 232, 239 and 247nm) and losartan potassium (at 206nm) simultaneously present in solution. Prior to these studies, the validity of the spectrophotometer assay methods for individual drugs was checked with the reference drugs, where a correlation coefficient of 0.999 was obtained.

The availability of simvastatin after $3 \mathrm{hrs}$ was found to be $100 \%$ at 232 , 239 and $247 \mathrm{~nm}$ in all $\mathrm{pH}$ mediums. However, availability of simvastatin in presence of losartan potassium after $3 \mathrm{hrs}$ at $37^{\circ} \mathrm{C}$ in simulated gastric juice, $\mathrm{pH}$ 7.4 and $\mathrm{pH} 9.0$ was found to be $0.0 \%$ indicating that simvastatin was inhibited by losartan, forming a charge-transfer complex in which all the three active (chromophoric) sites of the drug were employed. It was further confirmed form the UV spectrum of simvastatin-losartan interaction where by all the three peaks of simvastatin was completely diminished.

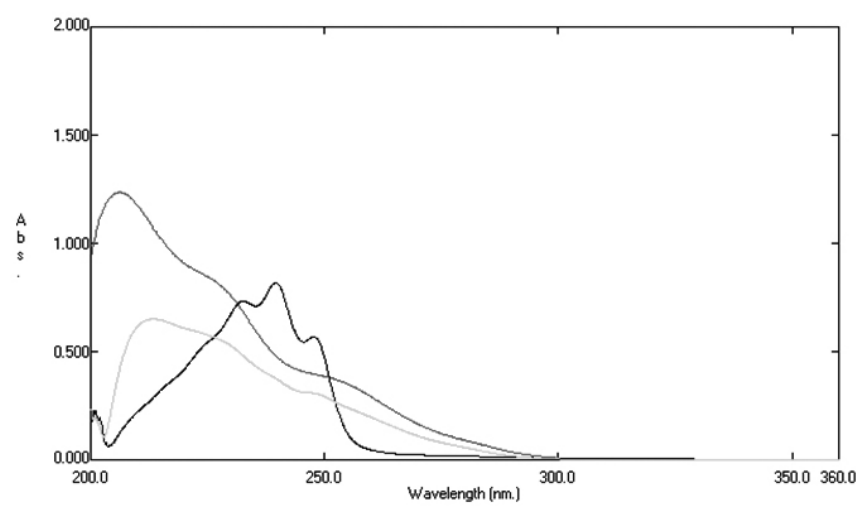

Figure 3: UV absorption spectrum of Simvastatin reference standard (black), Losartan potassium (red) and Simvastatin-Losartan interaction (green).

On the other hand, the availability of losartan potassium was immensely increased due to complex formation, the molar absorptivity of which was greater than the individual drug. In $\mathrm{pH} 4$ availability of simvastatin was found to be $27.02,23.85$ and $28.38 \%$ corresponding to $232,239,247 \mathrm{~nm}$ respectively, again indicating the complex formation, but to a lesser extent.
Thermodynamic properties of the charge-transfer complex such as the change in enthalpy $\Delta H$, entropy $\Delta S$ and free energy $\Delta \mathrm{G}$, associated with complex formation, provide useful information regarding the nature and strength of binding. These thermodynamic quantities can be determined from the knowledge of equilibrium constant $\mathrm{K}$ for complex formation and its variation with temperature. Therefore, to study these parameters of the reaction, similar studies were carried out at 48 and $60^{\circ} \mathrm{C}$. After $3 \mathrm{hrs}$, in all dissolution mediums availability of losartan was found to increase at elevated temperatures. This increase in the availability of losartan with temperature was due to the stabilization of the charge-transfer complex at higher temperatures. The calculated availability of losartan was beyond $100 \%$ even after $15 \mathrm{~min}$ indicating that not only that complexation reaction was rapid but the molar mass and absorptivity of the complex formed was greater than the individual drug. Hence, the equilibrium constant K, could not be calculated.

On the contrary, simvastatin was not at all available in simulated gastric juice and in $\mathrm{pH} 7.4$ and 9.0 even at high temperatures. At $48^{\circ} \mathrm{C}$ simvastatin was available only in $\mathrm{pH} 4.0$ which scavenged at $60^{\circ} \mathrm{C}$. The formation of the complex was further proved from the melting points of the complex compared with the individual drugs and from the study of the infrared spectra of simvastatin, losartan and their charge transfer complex (figure 4). The melting point of simvastatin and losartan was in the range $135-138$ and $133.5-134.5^{\circ} \mathrm{C}$ respectively while that of the complex was $200^{\circ} \mathrm{C}$.

FTIR analysis showed that the sharp free $\mathrm{OH}$ stretching band of simvastatin at $3554 \mathrm{~cm}^{-1}$ was changed into a broad band extending from $3600-3100 \mathrm{~cm}^{-1}$ in the spectrum of the complex which was due to its both alcoholic and carboxylic $\mathrm{OH}$ group, hydrogen bonded to the carboxylic group of losartan. The NH stretching absorption of losartan at $3000 \mathrm{~cm}^{-1}$ was found to be broader and more intense in the spectrum of the complex. The carbonyl stretching vibration at $1730 \mathrm{~cm}^{-1}$ due to both the cyclic and non-cyclic ester group of simvastatin was shifted to the right in the spectrum of the complex and its intensity was considerably decreased. This was due to the opening up of the lactone ring into hydroxy acid. The C-O, C-N and C-Cl stretching absorption of losartan at 1000, 1259 and $750 \mathrm{~cm}^{-1}$ respectively and two types of $\mathrm{C}-\mathrm{O}$ absorption of simvastatin, due to secondary alcoholic and ester group at 1100 and $1250 \mathrm{~cm}^{-1}$ was nearly diminished in the spectrum of the complex. The reduction in the peak intensity was attributed to strong electronic transition in the complex which comprises of both $\mathrm{n}-\pi^{*}$ and $\pi-\pi^{*}$ transitions.

Important ${ }^{1} \mathrm{H}$ NMR signals of simvastatin active metabolite was observed at chemical shifts of $3.2(\mathrm{~s}, 2 \mathrm{H},-\mathrm{OH}), 5.50(\mathrm{~s}, 1 \mathrm{H}$, cyclohexene), $5.97(\mathrm{~s}, 2 \mathrm{H}$, ethylene) and $11.0(\mathrm{~s}, 1 \mathrm{H}, \mathrm{COOH})$ while ${ }^{1} \mathrm{H}$ NMR signals of losartan active metabolite was observed at chemical shifts of $4.2(\mathrm{~s}, 1 \mathrm{H}$, tetrazole), 7.12$7.28(\mathrm{~m}, 4 \mathrm{H}$, phenyl), 7.36-7.54 (m, 4H, phenyl) and $10.89(\mathrm{~s}, 1 \mathrm{H}, \mathrm{COOH})$. On comparing main peaks of the reference drugs with their complex, it was observed that in the ${ }^{1} \mathrm{H}$ NMR spectrum of the complex, the absorbance of the acidic $\mathrm{COOH}$ proton was shifted to the left (near $12.5 \mathrm{ppm}$ ) which is indicative of the presence of hydrogen bonding; more the hydrogen bonding takes place, the more deshielded a proton becomes and its absorbance is shifted to the left. Further, aromatic protons exhibited a $0.3-0.5 \mathrm{ppm}$ downfield shift in the complex spectrum. This fact could be explained from the increased electron density in the biphenyl ring owing to $\pi$ - $\pi^{*}$ transition ${ }^{28}$.

The charge-transfer complex formed is found to be associated with inter and intra molecular rearrangement of the electronic cloud of both the interacting drugs. This rearrangement involves a transfer of electron cloud or part of it from one component of the complex to the other. In the proposed structure of the complex, there exist two types of electronic transitions, an intense $\pi-\pi^{*}$ transition of the carbonyl group of simvastatin extended over the biphenyl ring of losartan (shifting and decrease in intensity of carboxyl peak of simvastatin at $1730 \mathrm{~cm}^{-1}$ ) (fig 4) and a weak $\mathrm{n}-\pi^{*}$ transition which exist between the lone pair of tetrazole nitrogen of losartan and conjugated diene group of simvastatin (multiple transitions at $1600-1450 \mathrm{~cm}^{-1}$ ) (fig 5). The $\pi$ electron cloud of simvastatin is disturbed as a result of which its availability is enormously decreased. Moreover, since the active metabolite of both drugs contain carboxylic and hydroxyl groups, it is proposed that the complex may further be stabilized due to the presence of strong hydrogen bonding (fig 6)

In our previous study, we observed that in simulated human body environment both atorvastatin, a HMG Co-A reductase inhibitor and losartan potassium formed associated complex ${ }^{29}$. However unlike simvastatin, the availability of atorvastatin was elevated while that of losartan was depressed because after complexation the $\pi-\pi^{*}$ transition at the tetrazole ring of losartan was disturbed as a result of which its availability was enormously decreased. 


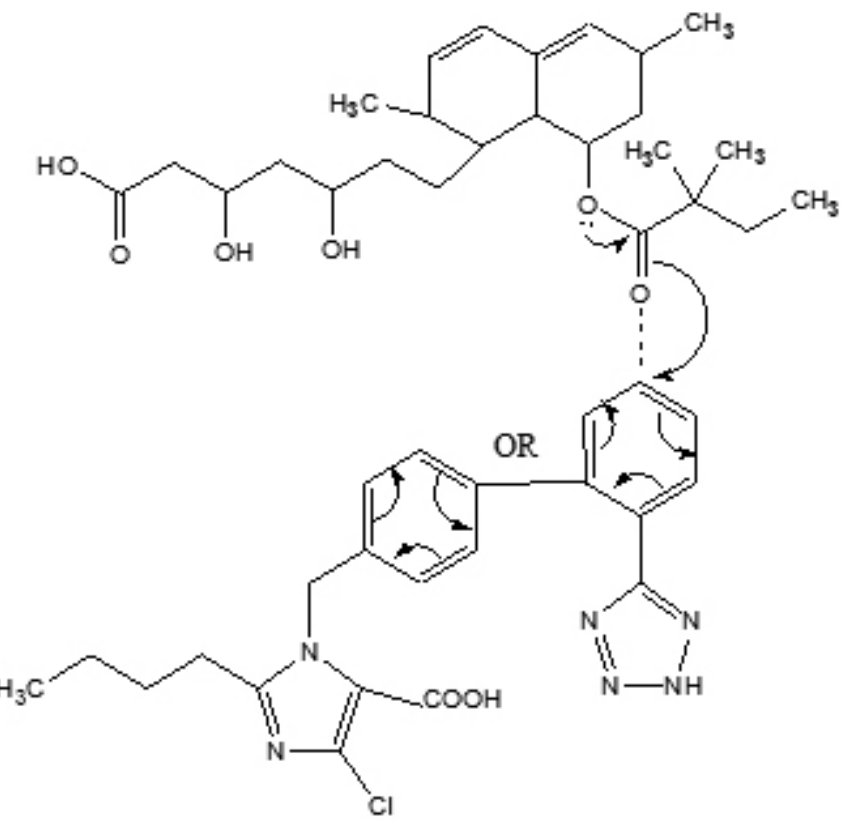

Figure 4

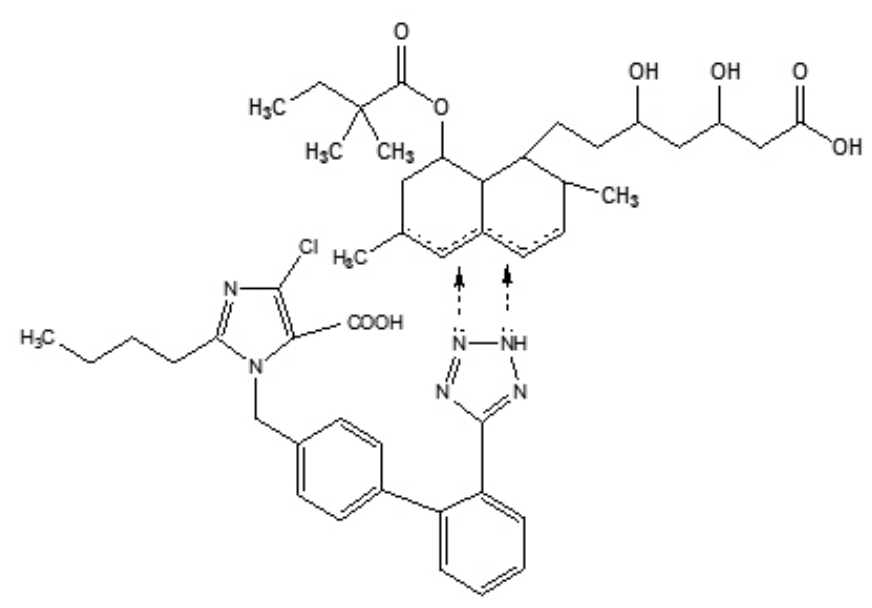

Figure 5

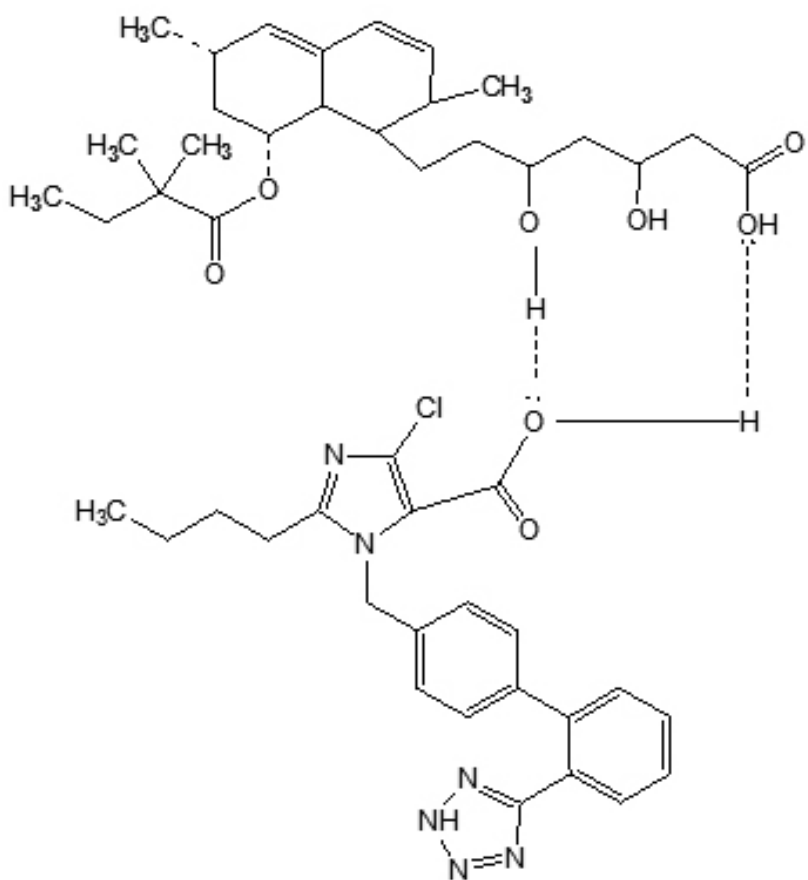

Figure 6

\section{CONCLUSION}

In summary our studies suggests that in vitro availability of simvastatin in presence of losartan decreases immensely which reflects its complexation with the drug. However, more tests (in vivo, etc.) should be performed to confirm these interactions in clinical practice.

In literature there are many evidences which suggest additive beneficial effects of simvastatin combined with losartan in the treatment of hypercholesterolemia, hypertensive patients ${ }^{30}$.One major cause for the observed beneficial effects on lipid profile and blood pressure with their combination therapy may be due to the formation of a charge-transfer complex. As a result, the delivery of both drugs into the circulation would be altered by the physicochemical interactions that occurred prior to their absorption. The rate of absorption of both drugs administered would partly depend upon the dissolution rate of the complex formed in the gastrointestinal fluid. As the complex slowly dissolves, both the drugs would be uniformly released; their availability and action in the body would prolong, producing a sustained release effect.

Potential advantages of such complexation : a. are maintenance of therapeutic effect for a considerable period of time and $b$. decreased incidence and/or intensity of undesired effects by elimination of the peak in drug concentration that often occur after administration of immediate-release dosage forms. Surveys that include data obtained in vitro tend to predict frequency of interactions that is higher than actually occurs, nevertheless, there are potential interactions of definite clinical importance, and the physicians must be alert to the possibility of there occurrence.

\section{REFERENCES}

1. K. Florey, Analytical profile of drug substances. 22, 362-382, (1993).

2. J. L. Sanchez-Quesada, C. Otal-Entraigas, M. Franco, O. Jorba, F. Gonzalez-Sastre, F. Blanco-Vaca, J. Ordonez-Llanos, Am J Cardiol. 84, 655-9, (1999).

3. J. McKenney, C. M. Ballantyne, T. A. Feldman, W. E. Brady, A. Shah, M. J. Davies, J. Palmisano, B. Mitchel, Medscape General Medicine. 7, 3, (2005).

4. A. T. Chiu, D. E. McCall, W. A. Price, P. C. Wong, D. J. Carini, J. V. Duncia, R. R. Wexler, S. E. Yoo, A. L. Johnson, P. B. Timmermans, J Pharmacol Exp Ther. 255, 711-718, (1990).

5. M. R. Goldberg, W. Tanaka, A. Barchowsky, T. E. Bradstreet, J. McCrea, M.W. Lo, M. Williams, T. D. Bjornsson, Hypertension. 21, 704-13, (1993). 
6. R. Gilad, Y. Lampl, Clin. Neuropharmacol. 22, 295-7, (1999).

7. T. Prueksaritanont, B. Ma, C. Tang, Y. Meng, C. Assang, P. Lu, P. J. Reider, J. H. Lin, T. Baillie, J Clin Pharmacol. 47, 291-8, (1999).

8. P. J. Gruer, J. M. Vega, M. F. Mercuri, M. R. Dobrinska, J. A. Tobert, Am J Cardiol. 84, 811-5, (1999).

9. W. R. Garnett, Am J Health-Syst Pharm. 52, 1639-1645, (1995).

10. T. Kantola, Clin Pharmacol Ther. 64, 177-82, (1998).

11. A. Szczeklik, J. Musia, A. Undas, P. Gajewski, P. Góra, J. Swadźba, M. Jankowski, J Am Coll Cardiol. 33, 1286-1293, (1999).

12. P. H. Hsu, Antimicrob Agents Ch, 45, 445-50, (2001).

13. G. E. Sander, T. D. Giles, Curr Hypertens Rep. 4, 458-463, (2002).

14. G. Nickenig, D. G. Harrison, Circulation. 105, 530-536, (2002).

15. G. Nickenig, Circulation. 110, 1013-1020, (2004)

16. British Pharmacopoeia, (2003), Her Majesty Stationery Office, 2, p. A 143 .

17. A. Iftikhar, M. S. Arayne, N. Sultana, Pak J Pharm Sci. 18, 55-60, (2005).

18. T. Takano, S. Abe, S. Hata, Biol Mass Spectrom. 19, 577-581, (1990).

19. H. Wang, Y. Wu, Z. Zhao, J Mass Spectrom. 36, 58 - 70, (2001).
20. J. J. Zhao, I. H. Xie, A. Y. Yang, B. A. Roadcap, J. D. Rogers, J Mass Spectrom. 35, 1133 - 1143, (2000)

21. G. Carlucci, P. Mazzeo, L. Biordi, M. Bologna, J Pharm Biomed Anal. 10, 693-7, (1992)

22. L Tan, L. L. Yang, X. Zhang, Y. S. Yuan, S. S. Ling, Se Pu. 18, 232-4, (2000).

23. N. Erk, Pharmazie. 57, 817-9, (2002).

24. S. Hillaert, B. W. Van den, J Pharm Biomed Anal. 31, 329-39, (2003).

25. R. C. Williams, M. S. Alasandro, V. L. Fasone, R. J. Boucher, J. F. Edwards, J Pharm Biomed Anal. 14, 1539-46, (1996).

26. D. L. Hertzog, J. F. McCafferty, X. Fang, R. J. Tyrrell, R. A. Reed, J Pharm Biomed Anal. 30, 747-60, (2002).

27. A. H. Prabhakar, R. Giridhar, J Pharm Biomed Anal. 27, 861-6, (2002).

28. M. Ruíz, L. Perelló, J. Server-Carrió, R. Ortiz, García-Granda.; M.R. Díaz, E. Cantón, J Inorg Biochem. 69, 231-239, (1998).

29. M. S Arayne, N. Sultana, U. Haroon, F. Qureshi, S. A. Ali, Pak J Pharm Sci. 19, 134-41, (2006).

30 K. Koh, M. J. Quon, S. H. Han, W. J. Chung, J. Y. Ahn, Y. H. Seo, M. H. Kang, T. H. Ahn, I. S. Choi, E. K. Shin, Circulation. 110, 3687-3692, (2004). 